\section{Estudo Debate}

em Testão Plamejamento
Revista Estudo \& Debate, Lajeado, v. 24, n. 3, 2017. ISSN 1983-036X

DOI: http://dx.doi.org/10.22410/issn.1983-036X.v24i3a2017.1326

\title{
A DÁDIVA DA SEMENTE: CONEXÓES DE SABERES ENTRE BRASIL E MOÇAMBIQUE
}

\author{
Eguimar Felício Chaveiro ${ }^{1}$, Helsio Amiro Motany de Albuquerque Azevedo²
}

\begin{abstract}
Resumo: Como as atividades de conexóes de saber podem contribuir para desenvolver uma consciência de solidariedade entre duas estruturas produtivas e sociais diferenciadas como é o cinturão verde do município de Inhambane (Moçambique) e o Cerrado goiano (Brasil)? Ao mesmo tempo poder-se-ia interrogar: como estudos dessa natureza poderão evitar futuros transtornos dos modelos que dilaceram a vida? - Os questionamentos apresentados são a problemática central deste trabalho, a partir do qual objetiva-se demonstrar e interpretar diferenças e similitudes entre Brasil e Moçambique com o intuito de identificar, a partir das experiências dos dois países em questão, a importância de se compartilhar saberes para contrapor o modelo de saber hegemônico gerador de vários efeitos deletérios à saúde humana; à preservação de espécies animais e vegetais, à convivência e à sociabilidade. $\mathrm{O}$ roteiro metodológico do artigo é complexo e resulta de pesquisa bibliográfica e documental, realização de trabalho de campo que privilegiou a observaçáo não participante, aplicação de questionários, realizaçáo de entrevistas com atores chaves, incluindo a realização de workshops com as associaçóes de agricultores. O pressuposto teórico conta com uma assertiva: há uma estreita ligaçáo entre o sistema-mundo atual e o modelo de saber hegemônico, de onde advém a inferiorizaçáo de outras modalidades de saber. Isso se traduz numa estratégia de dominação do sistema produtivo - e de vida - pelas grandes corporações mundiais de negócios.
\end{abstract}

Palavras-chave: Conexóes de saber. Dinâmica produtiva. Geopolítica dos saberes. Moçambique e Brasil.

Abstract: How the activities of knowledge connections can contribute to the development of an awareness of solidarity between two differentiated productive and social structures such as the green belt of Inhambane and the Cerrado of Goiás? At the same time, it could be questioned: how could studies of this nature prevent future disruptions of life-shattering models? - These questions are the central problem of this work. It aims to demonstrate and interpret differences and similarities between Brazil and Mozambique in order to identify,

1 Possui graduação em Geografia pela Universidade Católica de Goiás (1987), mestrado em Educação pela Universidade Federal de Goiás (1996) e doutorado em Geografia Humana pela Universidade de São Paulo (2001). Atualmente é professor associado da Universidade Federal de Goiás. É coordenador do Núcleo de estudos "Espaço, Sujeito e Existência”. Tem experiência na área de Geografia, com ênfase em Geografia Urbana, atuando principalmente nos seguintes temas: educação ambiental, a dinâmica da cidade, geografia urbana, geografia do trabalho e desenvolvimento urbano.

2 Graduado em Turismo pela Universidade Eduardo Mondlane (2006), mestre em Planeamento e Gestão Ambiental pela Universidade Católica de Brasília (2009) e doutor em Geografia pelo Instituto de Estudos Sócio-Ambientais da Universidade Federal de Goiás. Actualmente é docente na categoria de assistente e Director-Adjunto para a Investigação e Extensão na Universidade Eduardo Mondlane, Escola Superior de Hotelaria e Turismo. Foi bolsista da CAPES no programa PEC-PG (Doutoramento) e bolsista CNPq (Mestrado). 
from the experiences of the two countries, the importance of sharing knowledge to counter the hegemonic knowledge model that generates several deleterious effects on human health; the preservation of animal and plant species, coexistence and sociability. The methodological itinerary of the article is complex and results from bibliographical and documentary research, fieldwork that privileged non-participant observation, application of questionnaires, interviews with key stakeholders, including workshops with farmers' associations The theoretical assumption counts on an assertion: there is a close connection between the present world-system and the model of hegemonic knowledge, hence to the inferiorization of other modes of knowledge. This translates into a strategy of domination of the productive system - and of life - by the large global business corporations.

Keywords: Connections of knowing. Productive dynamics. Geopolitics of knowledge. Mozambique and Brazil.

\section{Introduçáo}

Os estudos e pesquisas (GONÇALVES, 2004; HARVEY, 2013) que notadamente se empenham em compreender o modelo produtivo atual, a organização dos saberes, o papel das universidades por meio da geopolítica mundial, insistem em afirmar o seguinte: há um vínculo estreito e uma adesão entre as formas de produzir, organizar e disseminar os saberes no modelo vigente de sociedade.

Essa constatação, especialmente entre os que interpretam a ecologia dos saberes, destaca-se Boaventura de Souza Santos, leva-os a estabelecer uma crítica: o modelo de saber edificado pela ilusão da separatividade, pela pressa e pelo fito economicista, tende a ignorar outros tipos de cultura, de percepção e de experiências simbólicas que não levem em conta as funçōes econômicas do saber.

Ora, isso redunda num grave problema, o ocultamento de experiências humanas realizadas e transmitidas durantes séculos em função da hegemonia de um saber profundamente erosivo atrelado ao fito economicista. A explosão biológica e química facultada pela transgenia; a eclosão da quarta revolução industrial com a nanotecnologia, com a energia cinética, incluindo a microeletrônica gera o que Arroyo (2014) denomina "destruição material do viver".

De forma a expor esse pensamento hegemônico e apresentar resultados, ainda que preliminares, desenvolve-se este trabalho que é resultado de missóes científicas que se realizaram em Moçambique e no Brasil, orientação de trabalhos em nível de graduação, mestrado e doutoramento, trabalhos de campos, workshops, entrevistas e realizaçóes de colóquios compartilhados, no âmbito do projeto de pesquisa "Sementes crioulas, quintais agroecológicos e cooperação popular: troca de saberes e experiências de economia criativa do cerrado brasileiro as savanas em Inhambane/Moçambique", financiado pela Coordenação de Aperfeiçoamento de Pessoal de Nível Superior, instituição brasileira. A partir deste projeto foram estabelecidas várias atividades de compartilhamento e conexóes de saberes entre profissionais dos dois países em questão. Pretende-se, igualmente, neste artigo, compartilhar as ações desenvolvidas e seus impactos reais e/ou potencias como forma 
de estimular mais parcerias Sul-Sul ${ }^{3}$ que contribuam, através da pesquisa e extensão, na mudança de paradigmas atrelados ao capitalismo "selvagem".

A problemática da pesquisa se situa na necessidade de perceber como as atividades de conexóes de saber podem contribuir para desenvolver uma consciência de solidariedade entre duas estruturas produtivas e sociais diferenciadas como o cinturão verde de Inhambane, localizado no município turístico de Inhambane em Moçambique e o Cerrado goiano, localizado no Estado de Goiás no Brasil, ao mesmo tempo que poderão evitar futuros transtornos dos modelos que dilaceram a vida?

Ao enunciar, no título, a expressão "as dádivas da semente" ${ }^{4}$, de maneira metafórica, chama-se a atenção para o envolvimento do saber que estabeleceu o processo de modernização do Cerrado goiano, baseado no rompimento da cadeia genética da reprodução da semente aniquilando os modos de cuidar da terra, de plantio e de cuidado com as plantas realizados pelas populaçóes tradicionais. Esse quase aniquilamento de uma cultura e de produzir dessas populaçóes têm gerado dependência aos grandes conglomerados do agronegócio, principalmente às grandes corporaçóes ligadas a comercialização de sementes transgênicas e outras. De dádiva, a semente tornou-se correia comercial, controle do processo produtivo e aniquilamento de saberes locais.

Ao referir-se à dádiva da semente chama-se a atenção, também, para interpretar-se o saber e a sabedoria local como sementes simbólicas, culturais, éticas, mediante as quais os pais educam os filhos; as famílias constituem os seus valores, as visóes de mundo, assim como as suas crenças. Por conseguinte, ceifar a fonte vital da semente significa romper o elo formador do ser humano.

O discurso lançado neste trabalho é um alerta aos gestores públicos sobre a necessidade de se (re) pensar numa produção que valorize e respeite as práticas sociais e a saúde humana, minimizando o uso de sementes e fertilizantes prejudiciais que, em muitas realidades, segregam comunidades e rompem as estruturas sociais dos grupos, enraizando a produção de monoculturas, a marginalização e precarização da qualidade de vida das comunidades afetadas.

3 Segundo o Fundo de População Das Naçôes Unidas (s.d) a cooperação Sul-Sul é a modalidade de cooperação técnica internacional que se dá entre países em desenvolvimento, que compartilham desafios e experiências semelhantes. Ela difere da tradicional Cooperação Norte-Sul (onde países desenvolvidos do Hemisfério Norte colaboram com países em desenvolvimento do Hemisfério Sul). A Cooperação Sul-Sul é uma das prioridades da política externa brasileira. Na última década, o Brasil tem investido esforços e recursos em programas voltados para países da América Latina e Caribe, África e Ásia (...).

4 A expressão dádiva da semente surge no bojo dos debates que se realizam no Grupo de Estudos Dona Alzira. Este grupo, entre outros assuntos aborda, analisa a produção em comunidades carentes e a necessidade destas serem hegemônicas neste processo, buscando experiências sobre bancos de sementes crioulas e reduzindo a dependência na utilizaçáo de sementes modificadas. 


\section{Procedimentos metodológicos}

A metodologia utilizada, no presente artigo, assenta numa base quali-quantitativa e participante realizada junto às associaçóes de camponesas pertencentes à União de Camponeses da Cidade de Inhambane (UCCI) e Camponeses do Estado de Goiás, entre os anos de 2014 e 2017.

Vale referenciar que este é parte dos resultados da pesquisa de cooperação internacional financiada pela Coordenação de Aperfeiçoamento de Pessoal de Nível Superior (CAPES), por meio do projeto "Sementes crioulas, quintais agroecológicos e cooperaçáo popular: troca de saberes e experiências de economia criativa do cerrado brasileiro as savanas em Inhambanel Moçambique" (CAPES/AULP/049/2014), realizado entre a Universidade Federal de Goiás (UFG) e a Universidade Eduardo Mondlane (UEM).

Durante o trabalho de campo, no Brasil e em Moçambique, foram utilizadas as técnicas de observação não-participante e a realização de entrevistas semiestruturadas, com aplicação de um formulário composto por perguntas (quantitativas e qualitativas), que correspondiam desde as características demográficas, econômicas e socioculturais até aos modos de organização, produção e comercialização de alimentos.

Os dados primários foram obtidos por meio de visitas em associaçóes camponesas em Inhambane e associaçóes e agricultores individuais no Brasil que praticam a agroecologia em diversos municípios do Estado de Goiás (Catalão, Itapemerim, Goiás, Cristalina, entre outros). Além do campo, foi realizada a pesquisa documental e bibliográfica; por meio de investigaçóes em obras literárias e periódicos relacionados aos temas: agricultura camponesa, agricultura em Moçambique e/ou Brasil, movimentos sociais do campo, agroecologia, soberania alimentar, transição agroecológica, dentre outros temas afins. As referências consultadas são principalmente oriundas do Brasil, de Moçambique e de outros países da América Latina; sendo em sua maioria intelectuais e movimentos/organizaçóes que atuam e refletem acerca do movimento agroecológico atualmente.

De igual modo, como metodologia, destaca-se a realização do I Workshop sobre Trocas de Experiências para Intervenção na Agricultura no município de Inhambane. Participaram da construção coletiva e da realização do Workshop: a União de Camponeses da Cidade de Inhambane (UCCI); a União Nacional de Camponeses (UNAC); extensionistas rurais do município de Inhambane; docentes e estudantes da Escola Superior de Hotelaria e Turismo de Inhambane (ESHTI); a Organização Rural para Ajuda Mútua (ORAM); a organização Engenharia Sem Fronteiras Catalunha-Espanha (com sede em Inhambane); o Conselho Municipal da cidade de Inhambane (CMCI) e estudantes brasileiras em intercâmbio em Moçambique. Tal atividade ocorreu na Escola Superior de Hotelaria e Turismo de Inhambane (ESHTI) e teve a duraçáo de três dias; mobilizando aproximadamente: trinta camponeses, quatro professoras da ESHTI, dez estudantes do Brasil e de Moçambique, dois extensionistas rurais de Inhambane, dois representantes do poder público local e funcionários da ESHTI.

Este foi um espaço para diálogos e formaçóes relacionadas a planificação e gestão de estratégias que visam à resolução dos principais desafios enfrentados pelos produtores rurais do município de Inhambane. 
Dessa forma, por meio da aproximação entre esses sujeitos e instituiçóes, para actividades de formação teórica e prática, no âmbito da economia criativa e agro-ecologia, e da realização de rodas de conversa para trocas de saberes e experiências; compreende-se que poderá haver um avanço na resolução dos impasses existentes para a construção efectiva da conexão entre a produção agrícola local e o mercado no município de Inhambane.

\section{Brasil e Moçambique: diferenças e similitudes}

Uma observação rápida, especificamente ligada à indicadores e quantitativos, poderse-ia vislumbrar grandes diferenças entre Brasil e Moçambique. Enquanto o Brasil possui mais de 200 (duzentos) milhóes de habitantes, Moçambique possui apenas cerca de 26 (vinte e seis) milhóes (INSTITUTO NACIONAL DE ESTATÍSTICA DE PORTUGAL, 2015). O Brasil está situado entre os países que possui maior desenvolvimento em termos absolutos e Moçambique entre as menores (PROGRAMA DAS NAÇÓES UNIDAS PARA O DESENVOLVIMENTO, 2016).

A superfície territorial de Moçambique corresponde a $799.830 \mathrm{~km}^{2}$, incluindo $13.000 \mathrm{~km}^{2}$ de águas interiores e uma fronteira total de $4.212 \mathrm{~km}$, dos quais $2.685 \mathrm{~km}$ são fronteiras terrestres, $1.205 \mathrm{~km}$ de fronteira fluvial e $322 \mathrm{~km}$ de fronteira lacustre (MARRUPI, 2011). O Brasil possui mais de $80 \%$ da populaçáo residindo nas cidades e Moçambique perto de $70 \%$ em áreas rurais.

Enquanto o Brasil conheceu, desde 1930, um processo direto de ação do Estado na implementação da modernização do território, da agricultura e de sua urbanização, desenvolvendo um modelo submetido ao mundo rico (FURTADO, 2005), Moçambique ficou independente a partir do ano de 1975, buscou desenvolver um modelo produtivo coletivista baseado na cooperação e no autoconsumo (MOSCA, 2005).

Conforme apontam Abrahamsson e Nilsson (1994) e Mosca (2005), a partir da criaçáo do Estado moçambicano foi introduzida uma nova estrutura produtiva que se aportou na "socialização do campo" e na "cooperativização da produção e do trabalho". Essa estrutura exigiu a edificação de um regime de propriedade coletiva dos meios de produção.

Para o governo revolucionário da Frente de Libertação de Moçambique (FRELIMO), partido no poder desde a independência, ao desenvolver a socializaçáo do campo seria possível diminuir os problemas criados pela dispersão do povoamento, próprio da tradiçáo rural moçambicana. A forma coletiva de povoamento daria início à forma das aldeias comunais. Essas seriam estratégias de organizar a produção junto à sociabilidade por meio das empresas estatais e das cooperativas, mediante a ação do trabalho coletivo.

O modo espacial e vivencial do sistema produtivo seriam as machambas ${ }^{5}$ estatais cujo o objetivo era produzir alimentos para as primeiras necessidades e bens de exportaçáo. Elas seriam o núcleo e o centro produtivo. A criação das machambas ocorreria com base nas plantaçóes e aglutinaçáo de parcelas agrícolas pequenas advindas do abandono dos colonos portugueses. A necessidade de aumentar a produção, de criar um regime coletivo do trabalho

5 Expressão moçambicana para designar áreas onde se cultiva. Significado idêntico ao de roça no Brasil. 
e de distribuição dos bens e também o dever de produzir alimentos para a população urbana dependeria de uma modernização. Contudo, a proposta de modernização náo conseguiu atender os objetivos, principalmente pela mudança no sistema político a partir do ano de 1992. Observa-se, inicialmente, que esta política, além de depender de recursos do Estado, que eram inexistentes, gerou um choque cultural com o modo de produzir do camponês moçambicano (MOSCA, 2005).

Vários problemas foram surgindo, depois de uma etapa de euforia e de crescimento econômico. Dentre os problemas situam-se a falta de assistência do Estado relativo à oferta de sementes, meios de produçáo e bens de consumo. Um clima de insegurança e também de descontentamento foi crescendo juntamente com outros problemas de ordem climática, como a seca, cheias e a ausência de um mercado interno que pudesse fazer circular os produtos.

Junto a esses problemas consideram-se também problemas logísticos e de infraestrutura para tratar, armazenar e escoar os produtos. Resultou do modelo um déficit na produçáo de alimentos para o consumo, de maneira que o país importava mais que exportava. $\mathrm{O}$ déficit na balança comercial ia danificando a crença no regime e na eficiência coletiva das machambas (MOSCA, 2005).

Esta situação estrutural avolumou-se com os conflitos políticos e com a ação do Estado criando também uma cultura de dependência e de negociação burocrática para manter o governo no poder. Algumas análises explicitam que o regime implantado, saindo de uma espécie de pré-capitalismo para o socialismo sem modernizar as forças produtivas e sem garantir os meios de consumo e de sobrevivência, levou o país a uma estagnaçáo econômica diante do sistema mundo, mesmo que, em algumas circunstâncias, houvesse um aumento da taxa de crescimento econômico (MOSCA, 2005).

Tudo isso desembocou numa espécie de socialismo dependente com força burocrática do Estado cunhado por uma produção pequena e apenas ligada à sobrevivência (ABRAHAMSSON \& NILSSON, 1994). Mas esse socialismo não se verificava na totalidade do sistema, especialmente a vida urbana conta com a circulaçáo de mercadorias e com as estratégias do lucro.

Aos poucos, conforme verificou-se no trabalho de campo, principalmente em entrevistas com atores locais, públicos e privados, e em observaçôes realizadas no âmbito do Projecto de pesquisa "Sementes crioulas, quintais agroecológicos e cooperação popular: troca de saberes e experiências de economia criativa do cerrado brasileiro as savanas em Inhambane/Moçambique", a propriedade coletiva da terra, embora de controle estatal vai sendo "corroída" de maneira clandestina. Soma-se a isso o fato de grandes projetos de monocultura moderna e de exploração de minérios estarem sob a posse de países com alto poder de financiamento, como a China, Estados Unidos da América, África do Sul e, inclusive, o Brasil.

Diferente desse processo, o modelo desenvolvimentista brasileiro apostou numa modernização rápida. Conforme a síntese de Santos (2002), desde o ano de 1930, o Estado brasileiro desenvolveu políticas para transformar o território nacional num espaço da economia internacional. Sem propugnar nenhum modelo socialista, a aposta do Brasil 
nesta modernização colocou as riquezas territoriais, como solo, água, minério, ecossistemas, cultura, mão-de-obra, como ofertas para transformar o território num mero recurso econômico.

Isso fez proceder um modelo de economia extrovertida, isto é, vertida para fora. Sendo assim, a modernização desenvolveu as forças produtivas, fez o parque industrial crescer, estabeleceu sensíveis melhoras na logística e na infraestrutura, nas plataformas tecnológicas, inclusive fez crescer o mercado interno, custando, todavia, uma profunda desigualdade social travestida de desigualdade regional.

Para consolidar esse processo de rendição modernizante no Brasil, contou-se com a internalização de tecnologias e saberes advindas da denominada revolução verde ${ }^{6}$. E mais: foram estabelecidas estratégias territoriais para implementar no processo produtivo esse saber erosivo. Dentre as várias estratégias, uma delas foi a transformação do vasto território do Cerrado brasileiro e goiano numa fronteira agrícola produtora de alimentos e commodities.

Este processo transformou o Cerrado no quarto cinturão produtivo do país a partir da cultura de grãos, gado bovino, agrocombustível e minérios. A forma de monocultura mecanizada gerou uma concentração de terras e de capital, além de gerar a destruição das formas de produzir das comunidades tradicionais e camponesas. Isso impactou o modo de vida das populaçooes indígenas; a cultura camponesa, de povos indígenas e quilombolas; contaminou as águas; criou dependência aos grandes conglomerados multinacionais e tornou o trabalho precário (GOMES, 2007).

O modelo de modernização desigual criou um processo de migração, fazendo das cidades, especialmente das metrópoles, o território da violência, da segregação e da desigualdade social; e transformando o campo num lugar de erosão de espécies vegetais e animais, originado também epidemias e doenças causadas por alimentação contendo agrotóxicos.

Sampaio (2016) interpreta essa dinâmica explicando que,

As grandes guerras mundiais do século XX possibilitaram vivenciar uma nova ordem mundial e redefiniram a divisão internacional da produção, do trabalho e da circulação. O campo, neste contexto, tinha funçóes definidas num mercado global, produzir para a indústria e consumir produtos industrializados, como agrotóxico, fertilizantes, máquinas, entre outros. O Brasil, historicamente como grande importador de produtos industrializados e exportador de matérias primas, foi obrigado a redimensionar o setor produtivo, impondo grandes transformaçôes em sua economia, intensificando o seu processo de industrialização e urbanização..." (SAMPAIO, 2016, p. 1).

Embora haja várias diferenças de conteúdos sociais; na estrutura demográfica; nos modelos de sociedade; nas açóes culturais, inclusive na sociabilidade, entre Brasil e Moçambique, há similitudes históricas consideráveis e interesses mútuos atuais. Dentre essas similitudes se situa o processo de colonização sofrido por ambos países. Observa-se,

6 A revolução verde, modelo baseado no uso intensivo de agrotóxicos e fertilizantes sintéticos na agricultura, hoje é um fato corrente no campo e está presente na vida de muitos produtores em diversas áreas do mundo (ANDRADES\&GANIMI, 2007) 
além disso, que uma das propostas moçambicanas atuais é estabelecer parcerias ao modo do modelo brasileiro a partir do projeto Pró-Cerrado.

Portanto, foi instituído o projeto Pro-Savana acordado entre os Estados brasileiro, japonês e moçambicano que visa a produção de gráos em vastas áreas de terra para exportação para o Japão com tecnologia brasileira (NISHIMORI, 2014), relegando a soberania alimentar de um país que enfrenta vários problemas de produção e distribuição de alimentos de primeira necessidade e com índices de subnutrição elevados. Segundo Carrilho et. al. (2016, p.3)

Estima-se que mais de metade das famílias em Moçambique estejam afectadas por insegurança alimentar e, cerca de um terço, por insegurança alimentar crónica. Cerca de $30 \%$ das famílias são consideradas pobres ou estão no seu limite em termos de diversificação da dieta e frequência de refeiçôes, uma medida crítica de segurança nutricional.

Conforme foi mencionado, o modelo brasileiro gerou vários problemas e múltiplas contradiçóes que tocam diretamente à saúde da população e à sua emancipação. Em decorrência disso, convém agora interpretar o tipo de saber que sustentou, não apenas a modernização brasileira, mas o sistema-mundo atual.

\section{O sistema-mundo e a geopolítica dos saberes}

Há uma correlação direta entre o modelo de mundo que foi sendo edificado no século XX, especialmente após a segunda guerra mundial, com os saberes constituídos para edificar esse modelo e para lhe consolidar. Descobertas, invenções e inovações, investimentos em laboratórios de pesquisa, controle de patentes, monopólio de determinados tipos de pesquisa, erigiu saberes de guerra; saberes economicistas; saberes produzidos por uma ciência cuja função é ser uma força produtiva.

Essas transformaçóes rápidas e impactantes exigem, na comunidade acadêmica, uma crítica aos problemas ambientais, ao modelo econômico que institui a desigualdade das naçóes e à violência social. Assim, como se crítica, no meio acadêmico, o modo pelo qual as emoçóes do sujeito contemporâneo trepidam, adoece e se vê rogando salvação. E, inclusive, uma crítica ao modo de vida urbana conformado por ruídos, competiçōes, privatismo e narcisismo, impóem uma crítica à hegemonia do saber e ao seu formato, à sua apropriação e disseminação.

Mais do que críticas exige-se elucidar as estratégias geopolíticas desse saber. Em outras palavras, poder-se-ia dizer: as descobertas da hidráulica, da mecânica, da eletricidade, da microeletrônica; a capacidade de conhecer o funcionamento químico e biológico da vida; as possibilidades de fluxos, de comunicação e armazenamento e representação de dados; a capacidade de explorar minérios, de fundir genes; e também de explorar outros planetas são correlatas com o que se chama "desgraça social", "miséria humana". Essa desgraça e miséria resultam de tamanha desigualdade que é acentuada cada vez mais em um período em que as técnicas se aprimoram para servir aos interesses do capital e não as demandas reais das sociedades que mais necessitam dela. 
Dentre as várias características do saber hegemônico consta: a inferiorização de outras formas de vida; o desprezo pela grande experiência da humanidade seja nas formas da medicina popular; da cultura popular; a profunda especializaçâa; o rompimento com a solidariedade de sujeitos na elaboração dos objetos de sobrevivência; a hierarquização das formas de representar a natureza (GONÇALVES, 2004; GOMES, 2007).

Além dessas características percebe-se o monopólio de alguns países e de corporações na manipulaçáo, posse, controle e uso dos saberes produzidos. Um dos efeitos pungentes dessa estratégia social de saber que, conforme foi apresentado, trabalha para a destruição material - e simbólica - da vida e do viver, é ceifar a corrente vital. O exemplo dessa castraçâoo é romper a dádiva das sementes. Isto é, uma das estratégias produtivas desse saber é minimizar a dependência da natureza fundindo espécies, criando o que tem sido chamado "melhoramento genético", e eliminando o poder de reprodução da semente quebrando, assim, a tradiçáo produtiva e dos modos de vida de populaçôes tradicionais e camponesas edificadas em milênios. A criação de sementes "suicidas" inferioriza os saberes remotos, faz emergir a dependência aos grandes laboratórios; coloca as comunidades humanas no círculo do dinheiro e inibe trocas de saberes sustentáveis (NASSER, 2015).

Ao invés do compartilhamento, da solidariedade, da transmissão gratuita e alegre dos valores,

\begin{abstract}
A humanidade tem se alimentado de milhares (8.500) de espécies de plantas. Hoje estamos condenados a comer milho e soja geneticamente modificados de diferentes formas. Quatro culturas principais - milho, soja, canola e algodáo - têm sido todas cultivadas às custas de outros cultivos, porque geram royalties por cada hectare plantado. A Índia, por exemplo, cultivava 1.500 tipos diferentes de algodão, e agora $95 \%$ são Algodão $\mathrm{Bt}$, geneticamente modificado, pelo qual a Monsanto recebe royalties. Mais de 11 milhôes de hectares de terra são empregados no cultivo de algodão. Destes, 9,5 milhōes são usados para cultivar a variedade Bt da Monsanto (SHIVA, 2016).
\end{abstract}

A afirmação de Shiva (2016) sugere que há necessidade de recuperar a dádiva da semente para estabelecer outra relação com a natureza, com a terra, com o ar, com a água e com o planeta. Em funçáo disso, os movimentos sociais, várias organizaçôes, setores da universidade têm desenvolvido estratégias de recuperação de sementes crioulas e nativas; estão criando formas de armazenamentos, trocando e disseminando experiências que não vão se extinguir por via das forças econômicas que são hegemônicas.

Ao recuperarem a dádiva da semente estabelecem conexóes de saberes, fazem trocas de sementes, propóem a libertaçáo da semente e do ser humano; mostram a ligaçáo cultural e vital do processo de conhecimento e a criaçáo de ambientes criativos e sadios. Se colocam contra a separatividade do saber hegemônico. Tentam ver níveis de ligações e de relações entre as esferas produtivas, culturais e emocionais. Propóem enxergar o grau de conectividade e de comunicabilidade entre as várias etapas da vida e do saber.

Um dos maiores críticos da espécie de saber que organizado e produzido a partir dos critérios classificatórios e separatistas, Edgar Morin, ensina que,

Era uma vez um grão de onde cresceu uma árvore, que foi abatida por um lenhador e cortada numa serraçáo. Um marceneiro trabalhou-a e entregou-a a um vendedor de móveis. 
O móvel foi decorar um apartamento e, mais tarde, deitaram-no fora. Foi apanhado por outras pessoas que o venderam numa feira. O móvel estava lá no adeleiro, foi comprado barato e, finalmente, houve quem o partisse para fazer lenha. O móvel transformou-se em chama, fumo e cinzas. Eu quero ter o direito de refletir sobre esta história, sobre o gráo que se transforma em árvore que se torna móvel e acaba fogo, sem ser lenhador, marceneiro, vendedor, que não vêem senão um segmento da história. É esta história que me interessa e me fascina (MORIN, 2007, p. 134).

Conforme está explicitado no texto de Morin (2007), há um processo integrado na existência das coisas e dos eventos, ou um entrelaçamento aberto e sistemático em que as variáveis se cruzam e formam redes causais e de redes de implicamentos. É sobre essa condição completa, integrada e totalizante que age o conhecimento, desafiando as instituições também para apresentar planos práticos à consecução da vida de forma particular ou em redes que dinamizam açóes coletivas que visem a qualidade de vida das comunidades nas quais estas se inserem.

O modelo econômico fundado na matriz modernizadora do Cerrado brasileiro foi constituído por outro paradigma: trata-se do paradigma da separatividade. Com objetivos exclusivamente economicistas e com funções geopolíticas, a ação do conhecimento científico e tecnológico que criou adubos, fornecidas, sementes transgênicas, agrotóxicos, implicou num conjunto de efeitos deletérios, entre os quais pode-se citar: (1) redução da biodiversidade; (2) erosão do solo; (3) extinção de nascentes; (4) contaminação de águas superficiais e dos lençóis, (5) intoxicação de animais; (6) desaparecimento de saberes das populaçôes tradicionais; (7) grilagem de terras indígenas; (8) extermínio de povos indígenas; (9) migração de camponeses e (10) violência social e urbana (GOMES, 2007; CHAVEIRO, 2010).

Ora, esses efeitos recaem nos ecossistemas; nos modos de vida; na saúde do trabalhador; no sistema cultural. Convém, contudo, advertir, tal como enunciou Castilho (2014), que a inovação é sempre necessária, pode contribuir para melhorar a produção de alimentos e para conhecer as potências dos componentes naturais, mas náo pode ter um fito apenas economicista, aniquilando valores humanos sustentáveis. Qualquer projeto de conhecimento e de intervençáo social que não leve em consideração a centralidade do ser humano como universo de valor, de cuidado e de respeito, tende a criar a miséria existencial limitando o desenvolvimento local.

Embora a modernização territorial e da agricultura do Cerrado brasileiro se constituiu como uma hegemonia de classe, pois favoreceu os grandes conglomerados econômicos e os latifundiários, bem como os bancos, houve - e ainda há - resistência, lutas para criar alternativas, meios que são animados por outros paradigmas e categorias, como a agroecologia; as feiras de semente crioulas; as feiras do produtor; produção com base coletiva em assentamentos; criação de programas baseados na economia solidária; museus de sementes indígenas; festivais de cultura popular; troca de sementes; criação de eventos, cursos e açôes formativas no campo da permacultura; desenvolvimento de práticas comerciais baseadas na rede de solidariedade e cooperativismo. Estas práticas que aproximam pessoas e lhes criam sentido de existência, a nosso ver, são modelos que devem ser "exportados" e 
divulgados pela capacidade de gerar simetrias e continuidade de exploração "să" de recursos naturais e culturais.

Portanto, a semente, principalmente aquela que brota sem químicos e outros malefícios, deve ser valorizada e resgatada para socializar a produção sustentável e garantir que as comunidades produtoras se tornem mais "hegemônicos" na produção de alimentos saudáveis.

\section{Trocas de experiências: o cinturáo verde de Inhambane em Moçambique}

No sentido de desenvolver o projeto, a partir da ideia de troca de saberes, foram feitas várias missóes científicas de professores brasileiros juntamente com professores moçambicanos; assistentes técnicos; mestrandos, doutorandos e intercambistas, todos vinculados ao projeto mencionado. Destacam-se, desde o ano de 2014, quatro trocas de experiências nos dois sentidos (Brasil-Moçambique e vice-versa). Nessas missóes, além de reunióes de estudo, entrevistas, visitas orientadas, ocorreram trabalhos de campo, minicursos, workshops, conforme ilustra o mosaico fotográfico na figura 1 .

Figura 1 - Atividades de coordenação e trabalho de Campo realizados em Inhambane (Moçambique) e Goiânia (Brasil)

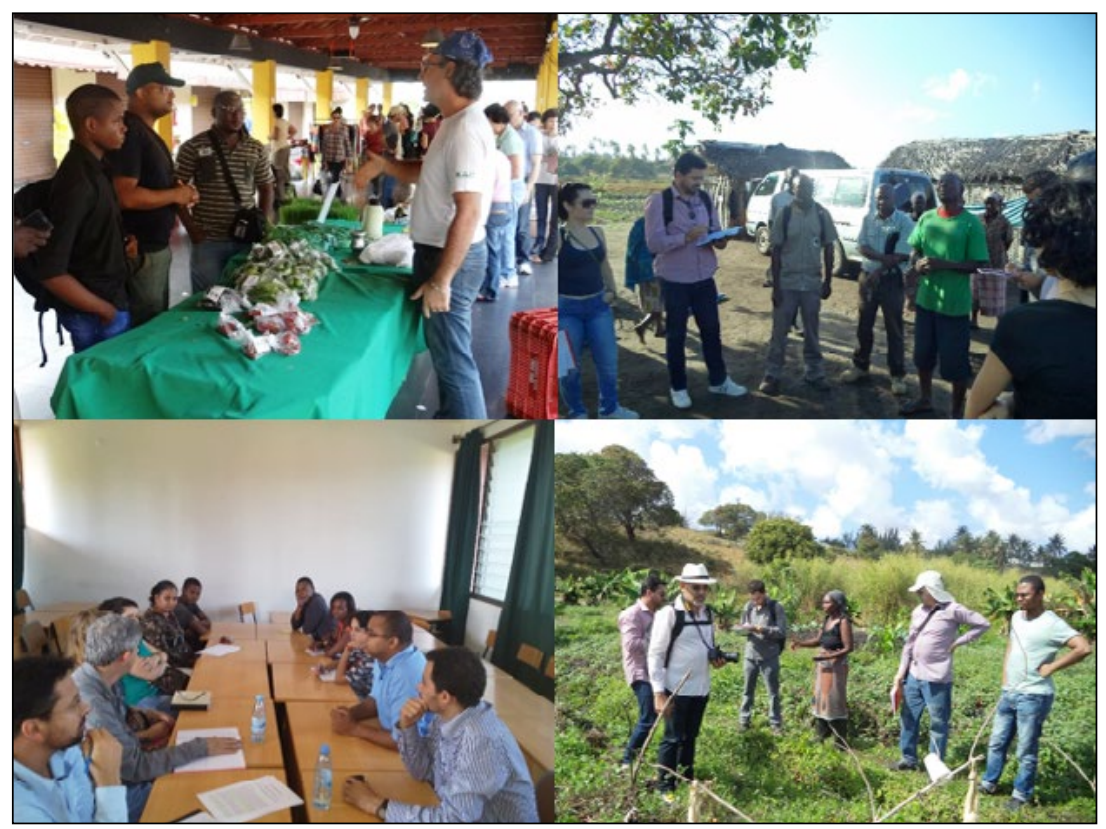

Fonte: Base de dados do Projecto, 2015.

O cinturão verde da Inhambane foi definido como lugar de contato. Foram contatadas, desde o ano de 2014, perto de quinze (15) associaçóes de camponeses em Inhambane e quatro associaçóes no Brasil, nas cidades de Goiânia, Goiás Velho, Catalão e Cristalina. 
As visitas, as rodas de diálogo e as demais atividades ocorreram no sentido de conhecer três aspectos: a dinâmica produtiva das machambas do Cinturão/Cerrado; o modo de organização dos camponeses; a relação entre os seus saberes e o circuito comercial.

Em Inhambane, o primeiro aspecto observado foi o fato de que a produção ocorre nas baixas, onde o solo possui maior teor de água, favorece ao processo de irrigação dos produtos hortfrutíferos; há mais matéria orgânica e menor composição de areia. Essa situação direciona a escolha dos lugares de plantio e reduz a área fértil, o que demanda do setor organizativo uma boa distribuição do solo.

O processo organizativo das associações depende do grau de amadurecimento, pois elas demandam sementes; assistência técnica; transporte; formação; e organiza a rede de pequenos comércios. Quando a associação não cumpre essas tarefas, a tendência é o processo produtivo e comercial ter uma marca individual e desdobrar-se em conflitos entre os membros.

A disposição coletiva das associaçôes conta com uma dinâmica: há associações que têm um calendário de reunião para se pensar o uso do solo, organizar as demandas, averiguar os problemas, distribuir sementes e tarefas. Há outras cuja participação dos membros é avaliada como deficitária. É pelas associações que se cria, nas machambas, situaçóes formativas, por exemplo, como o de criar adubos orgânicos, conforme ilustra a Figura 2.

Figura 2 - Produção de adubos orgânicos na Associação 7 de Abril no município de Inhambane

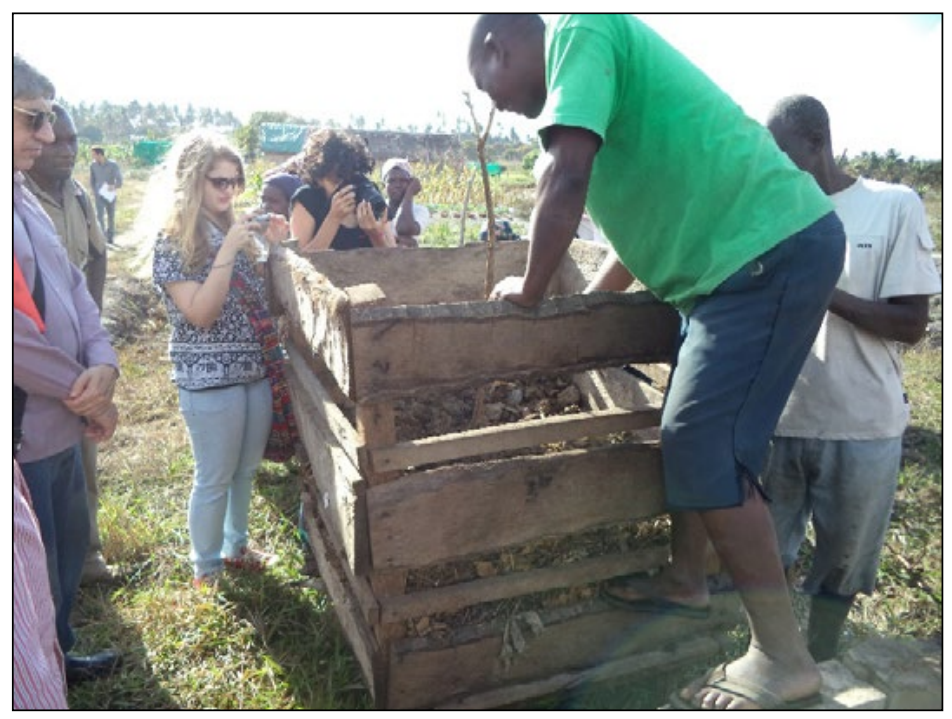

Fonte: Base de dados do Projecto, 2014.

Discutiu-se, nos minicursos do workshop, o papel dos defensivos; da distribuição de água; do envolvimento cultural dos associados e das possibilidades de comercialização em outros mercados como o setor do turismo que mantem a sua carteira de fornecedores 
de alimentos que privilegiam a importação de alimentos de outras cidades nacionais e estrangeira.

Os vínculos dos sujeitos da missão com os associados das machambas, em forma de diálogo aberto e diagnósticos, permitiram detectar vários problemas de múltiplas dimensões. Esses problemas, lidos sob o preceito das conexóes de saberes, são desafios para todas as partes: instituiçôes universitárias; gestores; assistência técnica e associações. Dentre os principais problemas, identificados no decurso da troca de saberes e trabalhos conjuntos desenvolvidos, pode-se citar:

- pouca participação de alguns membros das associações, o que pode conduzir a uma prática individualista no processo produtivo e implicar na fragilidade da associação na sua capacidade de demanda;

- necessidade de maior vínculo da assistência técnica. Para isso o Estado precisa disponibilizar mais técnicos extensionistas para assistirem as machambas;

- necessidade de criação de um banco de sementes e também de expedientes de armazenamento e conservação;

- rompimento da cadeia produção, circulação e consumo. Nem sempre os produtos gerados no Cinturão Verde têm garantia de vendas;

- falta de organizaçáo de um circuito de vendas a partir de paradigma, como o comércio solidário;

- desigualdade na produção entre os membros das associaçóes;

- incapacidade de legalização da terra e das próprias associações, visto que, muitas funcionam sem reconhecimento legal inibindo apoios formais de entidades que exigem o reconhecimento destas.

Todos esses problemas descritos esclarecem que a aglutinação entre a dimensão técnica dos saberes científicos com o setor organizativo juntando-se às práticas produtivas dos camponeses na terra demostram-se necessários para melhorar a condição de vida dos envolvidos, para aquecer o comércio local e gerar autonomia para os camponeses. Para isso, o setor formativo se coloca premente. Isso tem sido feito no projeto mediante várias práticas, uma dessas foi o workshop de apoio técnico aos camponeses associados.

O workshop foi um encontro entre os sujeitos e instituições envolvidas na actividade agrícola e turística do município de Inhambane, integrando a União dos Camponeses da cidade de Inhambane (UCCI), a União Nacional dos Camponeses de Moçambique (UNAC) os estudantes brasileiros em intercâmbio, a Escola Superior de Hotelaria e Turismo de Inhambane (ESHTI), a Organização Rural para Ajuda Mútua (ORAM), os Extensionistas Rurais locais, a Associação de Hotelaria e Turismo de Inhambane e o Conselho Municipal da Cidade de Inhambane conforme ilustra o mosaico fotográfico na Figura 3. 
Figura 3 - Momentos teóricos e práticos do workshop de apoio técnico aos agricultores (na esquerda a oficina de agroecologia e na direita a oficina de produçâo de adubos orgânicos)

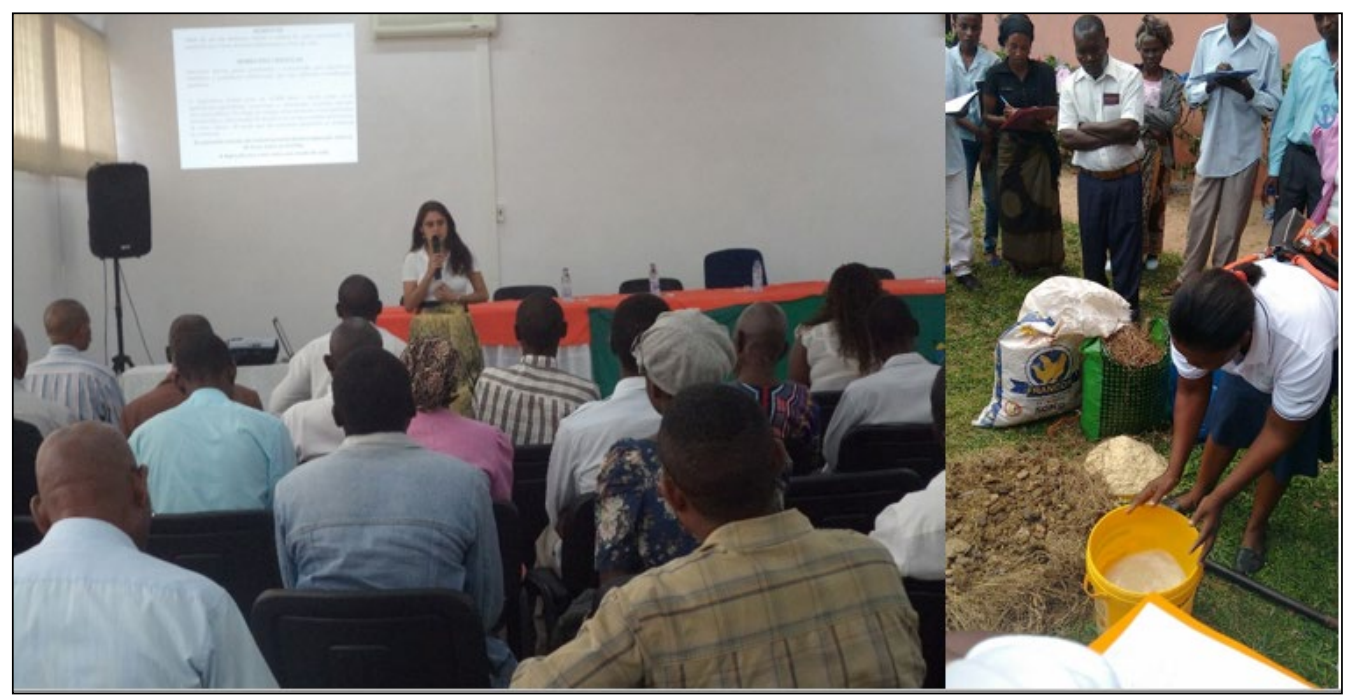

Fonte: Base de dados do Projecto, 2015.

Este evento técnico permitiu diálogos e formaçôes relacionadas a planificação e gestão de estratégias que visem à resolução dos principais desafios enfrentados por produtores rurais do município de Inhambane. Com base num diagnóstico prévio da produção e comercialização nas associações, realizado por Azevedo e Campos (2016), foram identificadas temáticas cruciais e resultantes das fraquezas e oportunidades identificadas.

Assim, neste encontro de dois dias, realizaram-se oficinas sobre: legalização de associações e terras, conflitos de terra, produção de sementes crioulas, o papel da UNAC, produção de adubos orgânicos, produção de pesticidas naturais, gestão de água e saneamento, a relação produção agrícola com o mercado turístico de Inhambane: potencialidades e estratégias de marketing, gestão financeira e associativismo.

Para além das trocas de saberes e conhecimentos, houve um momento para que os participantes, em grupo, identificassem pontos comuns relacionados aos desafios do sector agrícola neste território. Estes desafios foram apresentados aos gestores locais para que em coordenação com os demais intervenientes fossem desencadeadas articulaçóes para a resolução dos problemas. A presença de todos intervenientes foi essencial por ter possibilitado troca de experiências e definição de acçôes que visam garantir o desenvolvimento da agricultura, do turismo e do município.

Os resultados deste processo educativo compartilhado - o workshop - que emergiu das experiências e açóes desencadeadas entre docentes e investigadores da UEM e da UFG, começam a ser visíveis tendo em conta que parte destas associação está a reformular a sua forma de atuar na produção e comercialização, principalmente, buscando alternativas sustentáveis sem recurso a agrotóxicos e sementes adulteradas e cumprindo com técnicas 
que permitem conservar e transportar adequadamente os produtos produzidos, através de criação de espaços apropriados para seleção, separação e empacotamento dos alimentos.

Ademais, este trabalho inicial, garantiu a aprovação de outros projetos em Moçambique que irão dar continuidade e sustentabilidade às açóes formativas para melhoria do desempenho na produção agrícola e pecuária. Buscam-se, igualmente, outras oportunidades no Brasil e em Moçambique de expansão da iniciativa e de busca de experiências que possam ser transmitidas a título grátis aos associados, por meio de açóes de extensão universitária.

Portanto, um trabalho em rede e sem finalidades economicistas, através da extensão universitária, no contexto da cooperação para o desenvolvimento, é possível mesmo com tantas adversidades que existem de operacionalização. A planificação integrada e participativa faz com que os atores-chaves deste processo se engajem na busca e partilha de experiências e conhecimentos que permitam o desenvolvimento econômico de base solidaria alicerçado nos princípios da sustentabilidade, contribuindo para quebrar o paradigma atrelado ao capitalismo selvagem que se vive atualmente na escala planetária onde o lucro é a essência das relações de produção e troca.

Este resgate às práticas de produção sustentáveis é primordial para difundir, nas sociedades mais carenciadas, que a semente possui a dádiva de unir as pessoas para brotarem alimentos diversificados e saudáveis. De igual modo, que a Universidade joga um papel na disseminação de conhecimentos que tornem comunidades produtoras menos dependentes das grandes corporações.

\section{Consideraçóes finais}

As reflexóes apresentadas mostraram que a prática de conexóes de saberes invoca o diálogo e a intersecção entre a cultura científica e a cultura popular; invoca, também, as trocas de experiências a partir de problemas concretos e a necessidade de organizar coletivos que potencializem a leitura do mundo e a criação de renda e meios para a consecução de uma vida digna.

Percebeu-se ainda que há uma forma de saber para uma visão economicista da vida. Entende-se que o sistema-mundo atual contou com a participação ativa da ciência moderna gerando efeitos deletérios, os mais diversos, à vida dos ecossistemas, dos processos culturais, nas crenças e no respeito ao Outro. A chamada quarta revolução industrial, baseada na nanotecnologia, na transgenia, na energia cinética, pode criar inovaçóes, contudo têm-se constituído em saberes de guerra, de destruiçấo e expropriação dos direitos mais elementares.

Isso não quer dizer que se deve olvidar a necessidade da inovação, nem do avanço do conhecimento científico e tecnológico. Contudo, como se viu, não se pode criar saberes pretensiosos, egoístas e interesseiros que, ao invés de ser distribuídos e transmitidos entre gerações, são alvos de monopólios das naçôes ricas e dos grandes conglomerados econômicos.

Esse modo de realização dos saberes tem criado adoecimento dos sujeitos, extinção de parte do patrimônio genético e "exílio" do ser humano como núcleo de respeito, de cuidado e de potência vital. Esses saberes separatistas são igualmente saberes mercantis. Em função dessas consideraçóes e do que resultou das missóes científicas no Cinturão verde de 
Inhambane, convém enxergar os saberes como pauta de engajamento e como componentes das lutas de classe, da organização dos camponeses, da defesa da saúde, da educação e de um sistema produtivo que defenda a vida e não a destrua.

Descobriu-se nas atividades de pesquisa e extenso e na escuta dos camponeses, professores e intelectuais moçambicanos que, não apenas o Cinturão verde de Inhambane, mas o país inteiro, vive um dilema no setor de produção, de distribuição dos produtos e de incremento das forças produtivas. O regime político e o modelo produtivo desenvolvidos a partir da metade da década de 1970 não conseguiu solucionar problemas da produção, da inovação, da distribuição dos alimentos e principalmente da subnutrição que continua grave.

Esse dilema coloca na pauta repensar o modelo de desenvolvimento do país. A pesquisa em questáo, ao mostrar diferenças e similitudes entre Brasil e Moçambique, demonstrou que o paradigma de modernização do Cerrado brasileiro e especialmente goiano, através do Pró-Cerrado, próximo do que têm propugnado com o programa PróSavana, pode gerar vários problemas que tocam diretamente a manutençáo da vida digna da população moçambicana.

O que se viu no Cerrado brasileiro foi um modelo produtivo que violentou o modo de vida da população camponesa, indígena, quilombola; e, junto, violentou o gradiente genético da rica biodiversidade do Cerrado, suas águas, seus solos, seus lençóis e subsolos. Os estudos da modernizaçáo do território e da agricultura do Cerrado ajuízam que há uma forma de apropriação desse bioma-território por meio de intentos geopolíticos e mercantilistas, razão do seu viés destrutivo.

Os trabalhos, igualmente, mostraram a potencialidade da cultura e do povo moçambicano para açōes conectivas, sua disposição e disponibilidade para troca de experiências e para aprendizagem. Isso valida a importância da Universidade e a responsabiliza como agente dinamizador de dinâmicas locais, principalmente no campo da intervenção para o desenvolvimento local sustentado. Essa potência depende da dimensão organizativa dos trabalhadores; do setor de gestão e assistência técnica; de formação prática e intelectual; de logística e especialmente de projetos e programas que animem todos gerando um arco de força para enfrentar os problemas.

\section{Referências}

ABRAHAMSSON, H. e NILSSON, A. Moçambique em transição: um estudo da história do desenvolvimento durante o período 1974-1992. Trad. Dulce Leiria. Maputo e Gotemburgo: CEEI-ISRI e Padrigu, 1994.

ANDRADES, T. O. de; GANIMI, R. N.. Revolução verde e a apropriaçáo capitalista. CES Revista, v. 21, Juiz de Fora, 2007.

ARROYO, M. G. Outros sujeitos, outras pedagogias. Petrópolis - RJ: Vozes, 2014. 
AZEVEDO, H. A. M. A.; CAMPOS, M. P. Diagnóstico agrícola do município de Inhambane em Moçambique: possibilidades para o desenvolvimento da agroecologia. Revista Sapiência: sociedade, saberes e práticas educacionais, v. 5, p. 38-56, 2016.

CARRILHO, J. et. al. Desafios para a segurança alimentar e nutriçáo em Moçambique. Maputo: OMR, 2016.

CASTILHO, D. Modernização territorial e redes técnicas em Goiás. Goiânia, UFG: 2014.

CHAVEIRO, E. F. Cerrado e território: conflitos socioespaciais na apropriação da Biodiversidade - os povos indígenas Karajás, Aruanã-Go. Ateliê Geográfico, [S.1.], v. 4, n. 1, p. 64-83, dez. 2011.

FUNDO DE POPULAÇÃO DAS NAÇÕES UNIDAS. Cooperaçáo Sul-Sul.

Disponível em: http://unfpa.org.br/novo/index.php/sobre-o-unfpa/cooperacao-sul-sul. Consultado em 10.07.2017.

FURTADO. Celso. Formaçáo econômica do Brasil. São Paulo: Companhia Nacional de Letras, 2005.

GERMANO, M. G. Uma nova ciência para um novo senso comum. Campina Grande: EDUEPB, 2011.

GOMES, H.. Abordagens Geográficas do Cerrado: paisagens e diversidade. In: X EREGEO Simpósio Regional de Geografia. Catalão (GO), 6 e 9 de Setembro de 2007.

GONÇALVES, C. W. P. Geografia da riqueza, fome e meio ambiente: pequena contribuição crítica ao atual modelo agrário/agrícola de uso dos recursos naturais. R. Inter. Interdisc. INTERthesis, Florianópolis, v. 1, n. 1, 2004.

HARVEY, David. Os limites do capital. São Paulo: Boitempo, 2013.

INSTITUTO NACIONAL DE ESTATÍSTICA DE PORTUGAL. CPLP em números e figures 2015. Lisboa: INE, 2015.

MORIN, E. et al. Educar na era planetária. Brasília: Cortez, 2007.

MOSCA, J.. Economia de Moçambique século XX. Lisboa: Instituto Piaget, 2005.

NASSER, N.. Tecnologia Terminator: as sementes suicidas e...assassinas. Ecodebate: 2015. Disponível em: https://www.ecodebate.com.br/2015/04/13/tecnologia-terminatoras-sementes-suicidas-e-assassinas-artigo-de-nagib-nassar/. Consultado em 10.07.2017.

NISHIMORI, L.. Prosavana. [In: Tv Câmara - Programa Palavra Aberta]. Disponível em: https://www.youtube.com/watch?v=KrGyZhzfszo. Consultado em 10.12.2016. 
PROGRAMA DAS NAÇÓES UNIDAS PARA O DESENVOLVIMENTO. Relatório do Desenvolvimento Humano. Nova Iorque: PNUD, 2016.

SAMPAIO, V. S. Modernizaçáo da agricultura e seus rebatimentos nas relaçóes de trabalho no campo brasileiro. Disponível em: http://www.uesb.br/eventos/ebg/anais/8b. pdf. Consultado em 10.12.2016.

SANTOS, M. O retorno do território. In: SANTOS, Milton, SOUZA, Maria Adélia A. de; SILVEIRA, Maria Laura (Orgs.). Território: globalização e fragmentação. 5. ed., São Paulo: HUCITEC, 2002.

SHIVA, V. Vandana Shiva e a batalha das sementes. Disponível em: http:// outraspalavras.net/posts/vandana-shiva-e-a-batalha-das-sementes/. Consultado em 10.12.2016. 